\title{
Can We Set Quality Standards for the Centers: Minimally Invasive Surgery vs. Open Surgery in Colorectal Cancer Resection
}

\author{
Flich-Carbonell $\mathbf{J}^{1^{*}}$, Alfonso-Sanchez $\mathrm{JL}^{2,3}$, Alegre-Martinez $\mathrm{A}^{4}$, Gómez-Abril $\mathrm{S}^{1}$, Torres- \\ Sánchez T ${ }^{1}$, Martínez-Martínez MI ${ }^{5}$, Martín-Moreno $\mathbf{J M}^{2,6}$
}

${ }^{1}$ Colorectal Surgery Section, General and Digestive Surgery Service, Dr. Peset University Hospital, Valencia, Spain ${ }^{2}$ Department of Preventive Medicine, University of Valencia, Valencia, Spain

${ }^{3}$ Consortium General University Hospital of Valencia, Valencia, Spain

${ }^{4}$ Department of Biomedical Sciences, Cardenal Herrera CEU University, Valencia, Spain

${ }^{5}$ Department of Nursing, University of Valencia, Valencia, Spain

${ }^{6}$ University Clinical Hospital of Valencia, Valencia, Spain

"Corresponding Author: Flich-Carbonell J, Colorectal Surgery Section, General and Digestive Surgery Service, Dr. Peset University Hospital, Valencia, Spain, Tel: 34-669426183; E-mail: jflich@ comv.es

Received: 28 December 2019; Accepted: 10 January 2020; Published: 15 January 2020

Citation: Flich-Carbonell J, Alfonso-Sanchez JL, Alegre-Martinez A, Gómez-Abril S, Torres-Sánchez T, Martínez-Martínez MI, Martín-Moreno JM. Can We Set Quality Standards for the Centers: Minimally Invasive Surgery vs. Open Surgery in Colorectal Cancer Resection. Journal of Surgery and Research 3 (2020): 001-012.

\begin{abstract}
Background: Minimally invasive surgery (MIS) is the standard method for resection of colorectal cancer, but its indications have limitations that are constantly debated. In our study, the center had to meet the following four factors: surgeons should have considerable experience, there should be a high percentage of MIS, a low conversion rate, and good results in the intervention.
\end{abstract}

Methods: Retrospective observational study of a cohort of 948 patients with colorectal cancer who underwent scheduled open surgery (OS) and MIS between 20112016.

Results: There were no differences based on sex, body mass index, or location of the tumor, but OS was related to older age, higher ASA, a higher stage, previous surgery, and operative adverse events. The location of the primary tumor and the existence of synchronous 
tumors were related to variability in the technique. The implementation of MIS increased from 36.2\% in 2011 to $89.6 \%$ in 2016 . The surgeon's experience decreased the conversion rate from $6.5 \%$ in 2011 to $3.1 \%$ in 2016 , with $2 \%$ in $\mathrm{T} 0-2$ tumors. In logistic regression, the factor that most increased the possibility of choosing MIS was the pT grade of the tumor, and the factors that most contraindicated MIS were stages 2-4, ASA 4, stage 1, previous surgery, and advanced age.

Conclusions: In hospitals where surgeons have long experience, minimally invasive surgery could be implemented in up to $90 \%$ of cases, with low conversion rates (3-4\%) and good results for patients.

Keywords: Minimally Invasive Surgery; Open Surgery; Surgeon Experience; Conversion; Surgical Outcomes

\section{Introduction}

Minimally invasive surgery (MIS) in colorectal cancer resection $(\mathrm{CRC})$ is currently the standard method due to faster patient recovery and an oncological outcome similar to that of open surgery (OS) $[1,2]$. However, its indication may be a cause for discussion in patients with a high body mass index (BMI), ASA IV, previous OS, age over 80 years, pT4 tumors, and other factors, because of risk of a high conversion rate [3-5]. In randomized studies of MIS and OS in CRC resection, the conversion rates reach up to $30 \%$ [6]. Higher conversion rates are reported in T4 tumors, and studies have examined whether they will pose a greater risk of long-term local recurrence [4]. Other studies conclude that it is necessary to reduce the conversion rate through adequate patient selection for CRC resection with MIS by expert surgeons $[7,8]$. The years of experience of the surgeons and the number of MIS performed by the team may be factors in obtaining good results. This study is designed to provide information to obtain more accurate Journal of Surgery and Research knowledge about the limits of the indication of MIS performed in 2016 in a hospital center that meets three conditions: Its surgeons are experts (minimum 25 years in MIS), and there is a high percentage of MIS in CRC $(90 \%)$ and a low conversion rate $(3.1 \%)$.

\section{Material and Methods}

The study period ranged from January 2011 to December 2016. The information about the patients was collected prospectively in a database. This research project was approved by the Research Committee. Preoperative, operative, and postoperative data were collected at ninety days from all patients operated on consecutively using CRC resection. The hospital is a university tertiary public center that serves a population of 380, 000 people. A total of 1, 126 cases were recorded during that period, of which 948 corresponded to scheduled surgery and 178 to urgent surgery. Data collection was performed by one of the authors. We have conducted a retrospective observational study of the cohort of 948 patients undergoing scheduled surgery. The indication of the approach was considered in each case by the Clinical Expert Committee, using the preoperative extension study (colonoscopy, biopsy, and tattoo of carbon lesions, computed tomography in all cases, and magnetic resonance imaging in case of rectal involvement) and the preoperative review performed by the anesthetist with staging to grade I-IV using the classification of the American Society of Anesthesiology (ASA).

The data considered for the analysis were:

-MIS or OS and patient characteristics: sex, age, body mass index (BMI), ASA grade I-IV, tumor location (colon, rectum, or synchronous tumors included in the location of the most advanced tumor), TNM-AJCC classification (stage 0-IV), previous OS (except appendectomy and cholecystectomy), and adverse operative event. 
-Surgical resection procedures performed in the colon and rectum with MIS and OS. Histological result of tumor resection (pT) and nodes obtained. In the rectum, neoadjuvant chemo-radiotherapy and complete mesorectum were considered. In the postoperative period, mortality, hospital stay, and readmissions were considered.

-Conversion from MIS to OS, including strategic or preventive conversion due to the impossibility of progressing with the intervention due to adhesions, and reactive conversion due to an adverse operative event.

Conversions by tumor grade pT0-4a were studied separately, as well as those that required resection of other organs (small intestine, abdominal wall, ovary, uterine tube, uterus, bladder, prostate, seminal vesicles, segmental resection of iliac vessels) due to adhesion or tumor infiltration (pT4b) in ASA IV patients, previous OS, after operative adverse events, and in patients older than 80 years. The data were processed in SPSSv21IBM. Quantitative data are presented as mean \pm standard deviation, and qualitative data as frequency and / or percentage. The normality of the variables was studied. For the comparison of variables, Student's $t$ test was used with a 95\% Confidence Interval, and Pearson's Chi-square or Fisher's exact test were used when appropriate. Subsequently, a multiple logistic regression was performed to determine the factors that conditioned the performance of MIS or OS. The performance of MIS or OS was used as a dependent variable, and independent variables were factors related to both the patient and the surgery: age, sex, BMI, ASA, stage, resection of other organs, histological grade $\mathrm{pT}$ of the tumor, or previous surgery. Given the non-linear behavior of age, it was grouped in <60, from 60 to 69 , from 70 to 79 , and over 80 years. In a similar way, BMI was classified into four groups according to the World Health Organization Health guidelines [9]: normal and underweight (BMI <24.9), overweight (BMI 25.0-29.9), obesity $(\mathrm{BMI}<30.0)$.

\section{Results}

In all, 712 patients were intervened with MIS and 236 with OS. In the study of the patients in the analyzed series, there were no differences in sex, BMI, or tumor location, but the OS group had older age, higher ASA, a higher stage, previous OS, and operative adverse events (Table 1). Surgical resection procedures showed variability determined by the location of the primary tumor and the existence of a synchronous tumor (Table 2). The implementation of MIS (Table 3) increased from $36.2 \%$ in 2011 to $89.6 \%$ in 2016 (88.8\% in colon and $91.9 \%$ in rectum), with a global average over the six years of $75 \%$. In the rectum, neoadjuvant treatment was administered in $55.9 \%$ of the OS patients and in $50.2 \%$ of the MIS (Pearson's Chi-square-Fisher's exact test: $\mathrm{p}=0.810$ ). The results show that there is a relationship between the minimum years of experience of the surgeon and the conversion rate, which begins in the year 2011 with $6.5 \%$ and ends in the year 2016 with $3.1 \%$. The 90 -day postoperative mortality was $5.5 \%$ in OS and $0.6 \%$ in MIS (Pearson's Chi-square-Fisher's exact test: $\mathrm{p}=0.000), 21 \%$ due to tumor disease progression and $42 \%$ due to comorbidities. The average stay showed a median of 9 days in OS and 7 days in MIS (Student's t: $p=0.000 \quad 95 \%$ CI 1.5 3.9), and readmissions made up $5.5 \%$ in OS and $3.1 \%$ in MIS (Pearson's Chi-square-Fisher's exact test: $\mathrm{p}=0.109$ ).

The histological classification $\mathrm{pT}$ presented statistically significant differences (Table 4) because there was a greater indication of OS in pT4 tumors and a greater indication of MIS in pT0-3 tumors. There were 96 resections of other organs due to tumor adhesion or infiltration: 19 were reported histologically as T4a and 77 as T4b. The number of lymph nodes obtained in the colon in OS (13.7 \pm 8$)$ and MIS (11.9 \pm 7$)$ was slightly 
lower in MIS (Student t: $\mathrm{p}=0.006$ 95\% CI 0.51 3.01). In the case of the rectum, there were no significant differences between OS $(8.9 \pm 7)$ and MIS $(9.9 \pm 6)$ (Student's t: $\mathrm{p}=0.275$ 95\% CI -2.910 .83 ). The integral mesorecta in OS were $70.4 \%$, and in MIS $89.4 \%$, showing that MIS was statistically superior (Pearson's Chi-square-Fisher's exact test: $\mathrm{p}=0.001$ ). Simultaneous resection of CRC and liver metastasis was performed in five cases in MIS and six in OS. The overall conversion was $4.3 \%$ (Table 5). In general, the conversion rate increased with the difficulty of resecting pT4 tumors, and it ranged from $2 \%$ in $\mathrm{T} 0-2$ to $25 \%$ in $\mathrm{T} 4 \mathrm{~b}$. Conversion after operative adverse events occurred in $15 \%$ of OS and in $0.8 \%$ of the total in MIS. In ASA-IV, this percentage was $9.1 \%$, but it was lower in previous OS and patients over 80 years old. There was conversion (20\%) in simultaneous resection of CRC and liver metastases.
In the logistic regression involving OS vs. MIS (Table 6), the Omnibus test had a p-value of 0.00 , the Cox and Snell test gave a value of $20.6 \%$, and the Nagelkerke test yielded $30.7 \%$. The independent variable set model was statistically significant, explained between $20.6 \%$ and $30.7 \%$ of the dependent variable, and correctly classified $80.2 \%$ of the cases, and so we can accept the statistical model. The factor that most increased the possibility of choosing MIS over OS was the tumor's pT grade, in order of potency: T2 (OR 11.03), T3 (OR 7.6), $\mathrm{T} 1$, (OR 5.3). By contrast, the factors that most decreased the possibility of choosing MIS over OS were, in order of potency: stages 2-4 (OR 0.1), ASA 4 and stage 1 with OR of 0.2 , previous surgery (OR 0.4 ), and age over 80 years and 70-79 years with OR 0.5 and 0.6 , respectively. No statistically significant differences were found for sex, BMI, location of surgery (colon/rectum), resection of synchronous tumors, or resection of other organs.

\begin{tabular}{|c|c|c|c|c|c|}
\hline \multirow[b]{3}{*}{ Age } & \multicolumn{2}{|l|}{ OS } & \multicolumn{3}{|l|}{ MIS } \\
\hline & $\mathbf{m}$ & sd & $\mathbf{m}$ & sd & $P$ value \\
\hline & 71.9 & 11 & 68.6 & 11 & $0.000(1.43-4.79)^{\mathrm{a}}$ \\
\hline \multirow[t]{2}{*}{ Body Mass Index } & 27.3 & 5 & 28.6 & 13 & $0.164(-3.23-0.55)^{\mathrm{a}}$ \\
\hline & $\mathbf{n}$ & $\%$ & $\mathbf{n}$ & $\%$ & $P$ value \\
\hline \multicolumn{5}{|l|}{ Sex } & \multirow[t]{4}{*}{$0.442^{\mathrm{b}}$} \\
\hline Male & 139 & 58.9 & 440 & 61.8 & \\
\hline Female & 97 & 41.1 & 272 & 38.2 & \\
\hline Total & 236 & 100 & 712 & 100 & \\
\hline \multicolumn{5}{|l|}{$\overline{\text { ASA }}$} & \multirow[t]{5}{*}{$0.000^{\mathrm{b}}$} \\
\hline I & 11 & 4.7 & 41 & 5.8 & \\
\hline II & 103 & 43.6 & 402 & 56.5 & \\
\hline III & 105 & 44.5 & 255 & 35.8 & \\
\hline IV & 17 & 7.2 & 14 & 2.0 & \\
\hline \multicolumn{5}{|l|}{ Tumor location } & \multirow[t]{3}{*}{$0.213^{\mathrm{b}}$} \\
\hline Colon & 177 & 75.0 & 513 & 72.1 & \\
\hline Rectum & 59 & 25.0 & 199 & 27.9 & \\
\hline Synchronous $^{*}$ & 26 & 11.0 & 37 & 5.2 & $0.002^{b}$ \\
\hline
\end{tabular}




\begin{tabular}{|c|c|c|c|c|c|}
\hline \multicolumn{5}{|l|}{ Stage } & \multirow[t]{6}{*}{$0.000^{b}$} \\
\hline 0 & 20 & 8.5 & 100 & 14.0 & \\
\hline I & 26 & 11.0 & 163 & 22.9 & \\
\hline II & 63 & 26.7 & 210 & 29.5 & \\
\hline III & 70 & 29.7 & 171 & 24.0 & \\
\hline IV & 57 & 24.2 & 68 & 9.6 & \\
\hline Previous OS ${ }^{* *}$ & 51 & 21.6 & 75 & 10.5 & $0.000^{\mathrm{b}}$ \\
\hline $\mathrm{AOE}^{* * *}$ & 26 & 11.0 & 40 & 5.6 & $0.005^{\mathrm{b}}$ \\
\hline
\end{tabular}

*They were included in the colon or rectum group considering the predominant or more advanced tumor; **Cases with previous OS (laparotomies except appendectomy and cholecystectomy); ***Adverse Operatory Event;

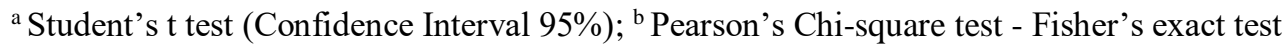

Table 1: Characteristics of patients operated on by open surgery (OS) and minimally invasive surgery (MIS).

\begin{tabular}{|c|c|c|c|c|c|}
\hline \multirow[t]{2}{*}{ Procedure } & \multicolumn{2}{|l|}{ OS } & \multicolumn{2}{|c|}{ MIS } & \multirow{2}{*}{$\begin{array}{l}\text { Total } \\
\mathbf{n}\end{array}$} \\
\hline & $\bar{n}$ & $\%$ & $\bar{n}$ & $\%$ & \\
\hline Right Colectomy & 74 & 28.5 & 187 & 71.5 & 260 \\
\hline Sigmoidectomy & 54 & 21.4 & 199 & 78.6 & 252 \\
\hline Anterior Resection of Rectum & 45 & 20.5 & 174 & 79.5 & 219 \\
\hline Enlarged Right Colectomy ${ }^{\mathrm{a}}$ & 20 & 23.8 & 64 & 76.2 & 84 \\
\hline Left colectomy & 14 & 28.0 & 36 & 72.0 & 50 \\
\hline Abdominal-Perineal Amputation & 13 & 37.1 & 22 & 62.9 & 35 \\
\hline Segmentary Colectomy ${ }^{\mathrm{b}}$ & 8 & 57.1 & 6 & 42.9 & 14 \\
\hline Total Colectomy $^{c}$ & 4 & 30.8 & 9 & 69.2 & 13 \\
\hline Subtotal Colectomy ${ }^{\mathrm{d}}$ & 1 & 16.7 & 5 & 83.3 & 6 \\
\hline Right Colectomy + Sigmoidectomy & 1 & 25.0 & 3 & 75.0 & 4 \\
\hline Right Colectomy + Anterior Resection of Rectum & 0 & 0.0 & 2 & 100 & 2 \\
\hline Left Colectomy + Anterior Resection of Rectum & 0 & 0.0 & 2 & 100 & 2 \\
\hline Total Colectomy + Anterior Resection of Rectum & 1 & 50.0 & 1 & 50.0 & 2 \\
\hline Right Colectomy + Left Colectomy & 0 & 0.0 & 1 & 100 & 1 \\
\hline Total Colectomy + Abdominal-Perineal Amputation & 0 & 0.0 & 1 & 100 & 1 \\
\hline TOTAL & 236 & 24.9 & 712 & 75.1 & 948 \\
\hline
\end{tabular}

${ }^{a}$ Resection of medium colic vessels; ${ }^{b}$ Resection of splenic angle; ${ }^{c}$ Resection of colon to upper rectus; ${ }^{d}$ Preservation of sigmoid colon

Table 2: Specific surgical resection procedure in open surgery (OS) and minimally invasive surgery (MIS). 


\begin{tabular}{|c|c|c|c|c|c|c|c|c|c|c|c|c|c|c|}
\hline Year & 201 & & 201 & & 2013 & & 201 & & 201 & & 201 & & Tot: & \\
\hline OS & $\mathbf{n}$ & $\%$ & $\mathbf{n}$ & $\%$ & $\mathbf{n}$ & $\%$ & $\mathbf{n}$ & $\%$ & $\mathbf{n}$ & $\%$ & $\mathbf{n}$ & $\%$ & $\mathbf{n}$ & $\%$ \\
\hline Colon & 52 & 59.8 & 48 & 43.6 & 28 & 22.4 & 22 & 18.0 & 15 & 10.8 & 12 & 11.2 & 177 & 25.7 \\
\hline Rectum & 29 & 72.5 & 10 & 25.0 & 9 & 19.6 & 1 & 2.7 & 7 & 12.1 & 3 & 8.1 & 59 & 22.9 \\
\hline Adverse event & 9 & 11.1 & 6 & 10.3 & 4 & 10.8 & 6 & 26.1 & 1 & 4.5 & 0 & 0.0 & 26 & 11.0 \\
\hline Number & 81 & 63.8 & 58 & 39 & 37 & 21.6 & 23 & 14.5 & 22 & 11.2 & 15 & 10.4 & 236 & 24.9 \\
\hline MIS & $\mathbf{n}$ & $\%$ & $\mathbf{n}$ & $\%$ & $\mathbf{n}$ & $\%$ & $\mathbf{n}$ & $\%$ & $\mathbf{n}$ & $\%$ & $\mathbf{n}$ & $\%$ & $\mathbf{n}$ & $\%$ \\
\hline Colon & 35 & 40.2 & 62 & 56.4 & 97 & 77.6 & 100 & 82.0 & 124 & 89.2 & 95 & 88.8 & 513 & 74.3 \\
\hline Rectum & 11 & 27.5 & 30 & 75.0 & 37 & 80.4 & 36 & 97.3 & 51 & 87.9 & 34 & 91.9 & 199 & 77.1 \\
\hline Adverse event & 4 & 8.7 & 3 & 3.3 & 9 & 6.7 & 11 & 8.1 & 10 & 5.7 & 3 & 2.3 & 40 & 5.6 \\
\hline Conversion & 3 & 6.5 & 6 & 6.5 & 8 & 6 & 1 & 0.7 & 9 & 5.1 & 4 & 3.1 & 31 & 4.3 \\
\hline Number & 46 & 36.2 & 92 & 61 & 134 & 78.4 & 136 & 85.5 & 175 & 88.8 & 129 & 89.6 & 712 & 75.1 \\
\hline Total & 127 & 100 & 150 & 100 & 171 & 100 & 159 & 100 & 197 & 100 & 144 & 100 & 948 & 100 \\
\hline $\begin{array}{l}\text { Minimum } \\
\text { years of } \\
\text { experience of } \\
\text { surgeon }\end{array}$ & 20 & & 21 & & 22 & & 23 & & 24 & & 25 & & - & \\
\hline
\end{tabular}

Table 3: Number of interventions in open surgery (OS) and minimally invasive surgery (MIS) in the colon and rectum, specifying the complication or adverse operative event and conversion according to the years of study.

\begin{tabular}{|l|l|l|l|l|l|l|}
\hline \multirow{2}{*}{} & \multicolumn{2}{l}{ OS } & \multicolumn{2}{l}{ MIS } & \multicolumn{2}{l|}{ TOTAL } \\
\cline { 2 - 7 } pT0 & $\mathbf{n}$ & $\mathbf{\%}$ & $\mathbf{n}$ & \% & $\mathbf{n}$ & \% \\
\cline { 2 - 7 } & 24 & 10.2 & 100 & 14.0 & 124 & 13.1 \\
\hline pT1 & 13 & 5.5 & 56 & 7.9 & 69 & 7.3 \\
\hline pT2 & 24 & 10.2 & 152 & 21.3 & 176 & 18.6 \\
\hline pT3 & 85 & 36 & 338 & 47.5 & 423 & 44.6 \\
\hline pT4a & 41 & 17.4 & 38 & 5.3 & 79 & 8.3 \\
\hline pT4b & 49 & 20.8 & 28 & 3.9 & 77 & 8.1 \\
\hline TOTAL & 236 & 100 & 712 & 100 & 948 & 100 \\
\hline
\end{tabular}

Pearson's Chi-square test - Fisher's exact test: $p=0.000$

Table-4: pT grade tumor in OS and MIS.

\begin{tabular}{|c|l|l|l|l|}
\hline \multirow{4}{*}{ Total } & \multicolumn{2}{|l|}{ Cases } & \multicolumn{2}{|l|}{ Conversion } \\
\cline { 3 - 5 } & $\mathbf{n}$ & $\mathbf{n}$ & \% & \% total cases \\
\cline { 3 - 5 } & 712 & 31 & 4.3 & 4.3 \\
\hline \multirow{2}{*}{ Colon } & 513 & 21 & 4.1 & \\
\hline
\end{tabular}




\begin{tabular}{|c|c|c|c|c|}
\hline Rectum & 199 & 10 & 5.0 & \\
\hline $\mathrm{pT}_{0}$ & 100 & 2 & 2.0 & \multirow[t]{3}{*}{0.3} \\
\hline Colon & 70 & 1 & 1.4 & \\
\hline Rectum & 30 & 1 & 3.3 & \\
\hline $\mathrm{pT}_{1}$ & 56 & 2 & 3.6 & \multirow[t]{3}{*}{0.3} \\
\hline Colon & 39 & 2 & 5.1 & \\
\hline Rectum & 17 & 0 & 0.0 & \\
\hline $\mathrm{pT}_{2}$ & 152 & 3 & 2.0 & \multirow[t]{3}{*}{0.4} \\
\hline Colon & 91 & 2 & 2.2 & \\
\hline Rectum & 61 & 1 & 1.6 & \\
\hline $\mathrm{pT}_{3}$ & 338 & 12 & 3.5 & \multirow[t]{3}{*}{1.7} \\
\hline Colon & 259 & 7 & 2.7 & \\
\hline Rectum & 79 & 5 & 6.3 & \\
\hline $\mathrm{pT}_{4 \mathrm{a}}$ & 38 & 5 & 13.1 & \multirow[t]{3}{*}{0.7} \\
\hline Colon & 34 & 4 & 11.8 & \\
\hline Rectum & 4 & 1 & 25.0 & \\
\hline $\mathrm{pT}_{4 \mathrm{~b}}$ & 28 & 7 & 25.0 & \multirow[t]{3}{*}{1.0} \\
\hline Colon & 20 & 5 & 25.0 & \\
\hline Rectum & 8 & 2 & 25.0 & \\
\hline ASA IV & 11 & 1 & 9.1 & 0.1 \\
\hline CA previous & 75 & 4 & 5.3 & 0.6 \\
\hline $\mathrm{AOE}^{*}$ & 40 & 6 & 15.0 & 0.8 \\
\hline$>80$ years & 128 & 7 & 5.5 & 1.0 \\
\hline
\end{tabular}

*Adverse Operatory Event

Table 5: Conversion of MIS to OS.

\begin{tabular}{|l|l|l|l|l|l|l|l|}
\hline Predictor Variables & $\begin{array}{l}\text { Beta } \\
\text { Coefficient }\end{array}$ & $\begin{array}{l}\text { Typical } \\
\text { Beta error }\end{array}$ & $\mathbf{p}$ & $\begin{array}{l}\text { Odds } \\
\text { ratio }\end{array}$ & $\begin{array}{l}\text { (CI 95\% } \\
\text { inferior })\end{array}$ & $\begin{array}{l}\text { (CI 95\% } \\
\text { superior })\end{array}$ \\
\hline MIS over OS & - & - & $\mathbf{0 . 0 1 4}$ & - & - & - \\
\hline Age: over $<60$ years & -0.066 & 0.287 & 0.818 & 0.936 & 0.534 & 1.643 \\
\hline $60-69$ years & -0.554 & 0.283 & $\mathbf{0 . 0 5 0}$ & 0.575 & 0.330 & 1.001 \\
\hline $70-79$ years & -0.799 & 0.308 & $\mathbf{0 . 0 1 0}$ & 0.450 & 0.246 & 0.824 \\
\hline$>80$ years & 0.147 & 0.195 & 0.452 & 1.158 & 0.790 & 1.697 \\
\hline Sex: female over male & - & - & 0.403 & - & - & - \\
\hline BMI: over normal/infra-weight & - & 0.213 & 0.424 & 1.185 & 0.781 & 1.798 \\
\hline Overweight & 0.170 & 0.247 & 0.179 & 1.394 & 0.859 & 2.264 \\
\hline Obesity & 0.332 & & & & 7
\end{tabular}




\begin{tabular}{|l|l|l|l|l|l|l|}
\hline ASA: over ASA 1 & - & - & $\mathbf{0 . 0 0 3}$ & - & - & - \\
\hline ASA 2 & 0.144 & 0.451 & 0.749 & 1.155 & 0.477 & 2.797 \\
\hline ASA 3 & -0.105 & 0.466 & 0822 & 0.901 & 0.362 & 2.243 \\
\hline ASA 4 & -1.645 & 0.645 & $\mathbf{0 . 0 1 1}$ & 0.193 & 0.055 & 0.683 \\
\hline Colon-Rectum: over colon & 0.104 & 0.213 & 0.626 & 1.109 & 0.731 & 1.684 \\
\hline Synchronous; over no & -0.360 & 0.323 & 0.264 & 0.697 & 0.370 & 1.313 \\
\hline Stage: over Stage 0 & - & - & $\mathbf{0 . 0 0 1}$ & - & - & - \\
\hline Stage 1 & -1.619 & 0.773 & $\mathbf{0 . 0 3 6}$ & 0.198 & 0.044 & 0.901 \\
\hline Stage 2 & -1.964 & 0.805 & $\mathbf{0 . 0 1 5}$ & 0.140 & 0.029 & 0.679 \\
\hline Stage 3 & -2.338 & 0.792 & $\mathbf{0 . 0 0 3}$ & 0.097 & 0.020 & 0.456 \\
\hline Stage 4 & -2.817 & 0.802 & $\mathbf{0 . 0 0 0}$ & 0.060 & 0.012 & 0.288 \\
\hline ROO*: over no & 22.265 & 8918.370 & 0.998 & max & 0.000 & $\max$ \\
\hline T: over T0 & - & - & $\mathbf{0 . 0 0 1}$ & - & - & - \\
\hline & 1.672 & 0.792 & $\mathbf{0 . 0 3 5}$ & 5.323 & 1.126 & 25.149 \\
\hline T2 & 2.401 & 0.768 & $\mathbf{0 . 0 0 2}$ & 11.030 & 2.450 & 49.658 \\
\hline T3 & 2.034 & 0.772 & $\mathbf{0 . 0 0 8}$ & 7.642 & 1.682 & 34.726 \\
\hline T4a & 1.064 & 0.810 & 0.189 & 2.897 & 0.592 & 14.169 \\
\hline T4b & 22.145 & 8918.370 & 0.998 & $\max$ & 0.000 & $\max$ \\
\hline Previous OS: over none & -1.004 & 0.236 & $\mathbf{0 . 0 0 0}$ & 0.366 & 0.231 & 0.581 \\
\hline Resection of on & & & & & \\
\hline
\end{tabular}

"Resection of other organs

Table 6: Factors associated with the choice of minimally invasive surgery (MIS) and/or open surgery (OS), and Conversion over No (only MIS).

\section{Discussion}

Since the introduction of colon resection by MIS in the early 1990s [10], this technique has been extended, and today its worldwide implementation is being studied [11] for CRC. Large randomized controlled trials have shown short-term advantages of this approach [12-14], and long-term oncology outcomes similar to OS [1520]. As mentioned in the introduction, of the three factors to consider in the centers, the first is the experience of the surgeons. In our center, the MIS was introduced for CRC resection in the early 1990s [21, 22] with a large group of surgeons who were experts in this technique. However, patients had always been selected from those who had a high probability that the intervention would be completed with a minimal risk of conversion, so that in 2011 we only recommended it in $36 \%$ of the cases of CRC. We decided to expand the indications in 2012, and 90\% CMI was reached in 2016 out of all the cases of CRC.

Based on the definition of Evidence-based Medicine and Surgery, which integrates clinical experience and patient values with the best available research information [23], it should be kept in mind that the first factor is clinical experience. All published works state the importance of surgeons' experience, but few studies describe it in detail. We consider that the years of experience of surgeons in MIS is the most important factor, and so in our case the number of years of 
experience of the main surgeon in the group was recorded. As a proxy for this aspect, other studies talk about training. Thus, the study carried out in the Netherlands [24] establishes that they began with the training of a select group of surgeons between 2003 and 2008; however, they established 24 as the number of resections by MIS necessary to be considered an expert. Other equivalents to training would be the boardcertified colorectal surgeons [25].

Other similar parameters to reflect the surgeons' experience are established according to the hospital volume of MIS, and so the study by Babberich, MP, et al. [26] refers to high-volume centers with more than $100 \mathrm{CRC}$, including more than 40 resections by MIS, although they show higher conversion rates, over $10 \%$ [27]. Other works try to measure this factor based on the number of expert surgeons who participated in the study. Here the variations are important. Thus, whereas some authors [28] talk about the same surgeon operating on all the patients, or surgeons trained by him, other authors [29] establish that there were 6 experienced surgeons who performed the MIS, and others are simply databases of all the patients who undergo resection for primary CRC in the Netherlands [26]. This audit collects information about the patient, the tumor, the treatment, and the characteristics of the short-term results of all patients.

The second factor we consider important is the percentage of MIS out of the total. The values are very different in the large number of studies that have been published on this aspect, such as those collected by Lorenzon L et al. [11]. However, some studies have obtained similar figures to those we found in our hospital, although somewhat lower for 2015 [26], 84\% for colon cancer and $89 \%$ for rectal cancer. The third factor we consider is conversion. In our study, there is a relationship between the surgeon's years of experience Journal of Surgery and Research and conversion, although other factors may have intervened. By contrast, there are studies such as Massaroti et al. [30] that do not associate the conversion rate with the surgeon's experience. However, we think this study does not have sufficient strength to prove otherwise because it was performed with 6 surgeons and a total of 408 MIS between 2009 and 2014, classifying surgeons as experts if they had done more than 100 MIS.

When considering the results, the 90-day postoperative mortality was $5.5 \%$ in OS and $0.6 \%$ in MIS (considering that $37 \%$ of the deaths were attributable to the surgery), and the average stay presented a median of 9 days in OS and 7 days in MIS. Moreover, among the results we must consider that the priorities of the patients surveyed after colorectal surgery [31] are freedom from cancer, stoma, and surgical complications, whereas the hospital stay, the MIS, and the appearance and duration of the incision have secondary importance. In our review, the ASA IV, previous OS, and age over 80 years did not present an excessive conversion rate compared to the global rate. For tumors and advanced stages (pT4 and stage IV), OS was indicated more, as in other studies [32], but MIS was indicated in 66 cases of pT4 tumors. In the review by Bretagnol et al [33] of 39 patients with T4 tumors, there was a conversion rate of $18 \%, 2.5 \%$ mortality, and $33 \%$ morbidity. Adverse operative events, mortality, and hospital stay were lower in MIS. The histological results were similar, but with $19 \%$ more full mesorectum in MIS, which can be explained by case selection. Logistic regression indicates that the only unfavorable factor in indicating MIS, and the highest conversion rate, is multi-visceral resection in T4 tumors, coinciding with other published works $[6,12]$, although some Societies' guidelines recommend OS in these cases [34]. 


\section{Conclusion}

The review allows us to conclude that our center has better results than those published in the literature, simply because its surgeons have developed a great MIS practice over the years and, therefore, a good indication for this approach. Therefore, we believe that the experience of surgeons who practice MIS should be described more precisely. Thus, in centers where surgeons have extensive experience, MIS could be implemented for CRC resection in up to $90 \%$ of cases, with low conversion rates close to $3-4 \%$ and good results for patients. We believe that, based on the number of articles published, it is time to start establishing quality standards of the Centers that practice this type of surgery.

\section{Funding}

There was no funding for this study.

\section{Conflict of Interest}

All authors declare that they have no conflict of interest.

\section{References}

1. Tanis PJ, Buskens CJ, Bemelman WA. Laparoscopy for colorectal cancer. Best Practice and Research: Clinical Gastroenterology 28 (2019): 29-39.

2. Tong G, Zhang G, Liu J, et al. A meta-analysis of short-term outcome of laparoscopic surgery versus conventional open surgery on colorectal carcinoma. Medicine 96 (2017): 8957.

3. Kuhry E, Bonjer HJ, Haglind E, et al. Impact of hospital case volume on short-term outcome after laparoscopic operation for colonic cancer. Surg Endosc 19 (2005): 687-692.

4. Stormark K, Soreide K, Soreide JA, et al. Nationwide implementation of laparoscopic surgery for colon cancer: short-term outcomes and long-term survival in a population-based cohort. Surg Endosc 30 (2016): 4853-4864.

5. Tekkis PP, Senagore AJ, Delaney CP. Conversion rates in laparoscopic colorectal surgery: a predictive model with, 1253 patients. Surg Endosc 19 (2005): 47-54.

6. Allaix ME, Furnée EJ, Mistrangelo M, et al. Conversion of laparoscopic colorectal resection for cancer: What is the impact on short-term outcomes and survival?. World journal of gastroenterology 22 (2016): 8304.

7. Giglio MC, Luglio G, Sollazzo V, et al. Cancer recurrence following conversion during laparoscopic colorectal resections: a metaanalysis. Aging clinical and experimental research 29 (2017): 115-120.

8. Ptok H, Kube R, Schmidt U, et al. Conversion from laparoscopic to open colonic cancer resection-Associated factors and their influence on long-term oncological outcome. European Journal of Surgical Oncology 35 (2009): 1273-1279.

9. WHO Expert Committee on Physical Status: the Use and Interpretation of Anthropometry. Geneva, Switzerland) and World Health Organization. Physical status: the use of and interpretation of anthropometry, report of a WHO expert committee. World Health Organization (1995).

10. Jacobs M, Verdeja JC, Goldstein HS. Minimally invasive colon resection (laparoscopic resection). Surg Laparosc Endosc 1 (1991): 144-150.

11. Lorenzon L, Biondi A, Carus $\mathrm{T}$, et al. Achieving high quality standards in laparoscopic colon resection for cáncer: A Delphi consensus-based position paper. Eur J Surg Oncol 44 (2018): 469-483 
12. Veldkamp R, Kuhry E, Hop WC, et al. Survival after laparoscopic surgery versus open surgery for colon cancer: long-term outcome of a randomised clinical trial. Lancet Oncol 6 (2005): 477-484.

13. Van der Pas MH, Haglind E, Cuesta MA, et al. Laparoscopic versus open surgery for rectal cancer (COLOR II): short-term outcomes of a randomised, phase 3 trial. Lancet Oncol 14 (2013): 210-218.

14. Guillou PJ, Quirke P, Thorpe H, et al. Shortterm endpoints of conventional versus laparoscopic-assisted surgery in patients with colorectal cancer (MRC CLASICC trial): multicentre, randomised controlled trial. Lancet 365 (2005): 1718-1726.

15. Buunen M, Veldkamp R, Hop WC, et al. Survival after laparoscopic surgery versus open surgery for colon cancer: long-term outcome of a randomised clinical trial. Lancet Oncol 10 (2009): 44-52.

16. Bonjer HJ, Deijen CL, Abis GA, et al. A randomized trial of laparoscopic versus open surgery for rectal cancer. N Engl J Med 372 (2015): 1324-1332.

17. Jayne DG, Thorpe HC, Copeland J, et al. Fiveyear follow-up of the Medical Research Council CLASICC trial of laparoscopically assisted versus open surgery for colorectal cancer. Br J Surg 97 (2010): 1638-1645.

18. Green BL, Marshall HC, Collinson F, et al. Long-term follow-up of the Medical Research Council CLASICC trial of conventional versus laparoscopically assisted resection in colorectal cancer. Br J Surg 100 (2013): 75-82.

19. Fleshman J, Sargent DJ, Green E, et al. Laparoscopic colectomy for cancer is not inferior to open surgery based on 5-year data from the COST Study Group trial. Ann Surg 246 (2007): 655-662.

20. Kuhry E, Schwenk W, Gaupset R, et al. Longterm outcome of laparoscopic surgery for colorectal cancer: a cochrane systematic review of randomised controlled trials. Cancer Treat Rev 34 (2008): 498-504.

21. Delgado F, Bolufer JM, Grau E, et al. Laparoscopic colorectal cancer resection: initial follow-up results. Surgical Laparoscopy Endoscopy and Percutaneous Techniques 9 (1999): 91-98.

22. Bolufer JM, Delgado F, Blanes F, et al. Injury in laparoscopic surgery. Surgical laparoscopy and endoscopy 5 (1995): 318-323.

23. Leape LL, Berwick DM, Bates DW. What practices will most improve safety?: evidencebased medicine meets patient safety. Jama 288 (2002): 501-507.

24. Bosker R, Groen H, Hoff C, et al. Effect of proctoring on implementation and results of elective laparoscopic colon surgery. Int $\mathbf{J}$ Colorectal Dis 26 (2016): 941.

25. Jabir MA, Brady JT, Wen Y, et al. Attempting a laparoscopic approach in patients undergoing left-sided colorectal surgery who have had a previous laparotomy: Is it feasible?. Journal of Gastrointestinal Surgery 22 (2018): 316-320.

26. De Neree tot Babberich MPM, Van Groningen JT, Dekker E, et al. Laparoscopic conversion in colorectal cancer surgery; is there any improvement over time at a population level?. Surgical endoscopy 32 (2018): 3234-3246.

27. Huscher CG, Bretagnol F, Corcione F. Laparoscopic Colorectal Cancer Resection in High-Volume Surgical Centers: Long-Term Outcomes from the LAPCOLON Group Trial. World J Surg 39 (2015): 2045-2051 
28. Shiga M, Maeda H, Oba K, et al. Safety of laparoscopic surgery for colorectal cancer in patients over 80 years old: a propensity score matching study. Surgery Today 47 (2017): 951-958.

29. De'Angelis N, Abdalla S, Bianchi G, et al. Robotic Versus Laparoscopic Colorectal Cancer Surgery in Elderly Patients: A Propensity Score Match Analysis. Journal of Laparoendoscopic and Advanced Surgical Techniques 28 (2018): 1334-1345.

30. Massarotti H, Rodrigues F, O'Rourke C, et al. Impact of surgeon laparoscopic training and case volume of laparoscopic surgery on conversion during elective laparoscopic colorectal surgery. Colorectal Disease 19 (2017): 76-85.
31. Wrenn S, Cepeda-Benito A, Ramos-Valdez D, et al. Patient Perceptions and Quality of Life After Colon and Rectal Surgery: What Do Patients Really Want? Diseases of the Colon and Rectum 61 (2018): 971.

32. Clancy C, O’Leary DP, Burke JP, et al. A meta-analysis to determine the oncological implications of conversion in laparoscopic colorectal cancer surgery. Colorectal Dis 17 (2015): 482-490.

33. Bretagnol F, Dedieu A, Zappa M, et al. T4 colorectal cancer: is laparoscopic resection contraindicated? Colorectal disease 13 (2011): 138.

34. Society of American Gastrointestinal and Endoscopic Surgeons (SAGES). Guidelines for laparoscopic resection of curable colon and rectal cancer (2012). 